\title{
Kant's Appearances and Things in Themselves as Qua-Objects
} Colin Marshall

\begin{abstract}
The 'one-world' interpretation of Kant's idealism holds that appearances and things in themselves are, in some sense, the same things. Yet this reading faces a number of problems, all arising from the different features Kant seems to assign to appearances and things in themselves. I propose a new way of understanding the appearance/thing in itself distinction via an Aristotelian notion that I call, following Kit Fine, a 'qua-object.' Understanding appearances and things in themselves as qua-objects provides a clear sense in which they can be the same things while differing in many of their features.
\end{abstract}

Kant's central claim concerning objects of experience is that they are appearances, not things in themselves. But there is a puzzle about how deep the distinction is between appearances and things in themselves. While Kant draws the distinction explicitly (e.g. "Appearances are not things in themselves" $\left.(A 165 / B 206)^{1}\right)$, he often implies that appearances and things in themselves are, in some sense, the same things. In the Prolegomena, Kant states that "it is only by means of the form of sensory intuition that we can intuit things a priori, though by this means we can cognize objects only as they appear to us... not as they may be in themselves" (Proleg. 4:283). Passages like this suggest that appearances and things in themselves are somehow different sides of the same entities. This implication is even clearer when Kant applies the appearance/thing in itself distinction to the self: Kant consistently writes of a single self that is both appearance and a thing in itself. $^{2}$

Unfortunately, Kant thinks the meaning of the distinction is obvious (cf. Groundwork for the Metaphysics of Morals, 4:451), and so devotes relatively little discussion to it.

\footnotetext{
${ }^{1}$ All passages from the Critique are cited in standard A/B pagination. Quotations are from P. Guyer and A. Wood (trans.), The Critique of Pure Reason (Cambridge UP, 1997). References to Kant's other works are given with the volume and page number from the German Academy edition: 1900-. Kants Gesammelte Schriften, German Academy of Sciences (ed.). Berlin: De Gruyter.. I cite the Prolegomena to Any Future Metaphysics as Proleg., with quotations from G. Hatfield (trans.), Prolegomena to Any Future Metaphysics (Cambridge UP, 2004).

${ }^{2}$ I argue for this in C. Marshall, 'Kant's one self and the appearance/thing-in-itself distinction', Kant-Studien (forthcoming).
} 
Broadly speaking, Kant's interpreters have taken two approaches to the distinction, privileging either the passages emphasising the distinctness of appearances and things in themselves or the passages emphasising their close relationship. These approaches have been called the 'two-world' and 'one-world' (or 'two-aspect') interpretations, respectively. Different interpreters use this terminology differently, and the details of each approach have been developed in a number of ways, but the basic point of contention is fairly stable. ${ }^{3}$

The traditional two-world interpretation holds that appearances are mental constructs (or merely intentional contents), so that all facts about appearances are either identical to or are directly grounded in facts about representations. It holds that things in themselves, by contrast, are mind-independent entities. The latter may cause or indirectly ground the former in some way, but the two are, on this approach, fundamentally different kinds of things.

The traditional one-world interpretation, as typically presented, holds that appearances and things in themselves are identical (or better: that each appearance is identical to some thing in itself). Talk of identity is attractive because this provides the clearest sense in which appearances and things in themselves could be the same things. In practice, however, it becomes less clear whether the one-world interpreters really mean to identify appearances and things in themselves. ${ }^{4}$ This emerges in the alternative formulation of the view, according to which appearances and things in themselves are two aspects of the same things. The talk of two aspects suggests that appearances and things in themselves are distinct aspects of the same things, and so not identical. While some interpreters write as though these formulations were equivalent, most interpreters seem to take the 'identity' formulation to be more metaphysically perspicuous. Allen Wood, for instance, labels the one-world approach 'the identity interpretation. ${ }^{15}$

\footnotetext{
${ }^{3}$ For a recent overview, see D. Schulting, 'Kant's Idealism: The Current Debate', in D. Schulting and J. Verburgt (eds.), Kant's Idealism: New Interpretations of a Controversial Doctrine (Dordrecht: Springer, 2011), pp. 1-25. Any one-dimensional characterisation of the debate will be contentious, and mine is surely no exception. But it will suffice for what follows.

${ }^{4}$ Here, and throughout this paper, I use 'identity' to describe strict, numerical token identity, which implies complete coincidence in properties. If some one-world interpreters have had (as I suspect) some other sense of 'identity' in mind, they have not made it clear what it was.

5 "We may call this the 'identity interpretation' because its fundamental point is that every appearance is identical to a thing in itself, and the distinction is not between two different entities but between two ways of thinking about or referring to the same entity", in A. Wood, Kant (Oxford: Blackwell, 2005), p. 65. Likewise, Gerold Prauss explains his interpretation as saying that "appearances and things in themselves... are
} 
In this paper, I propose an interpretation that differs from both traditional ones. This view does not identify appearances and things in themselves, but it gives both a strong sense in which they are the same things and a clear justification for talk of 'two aspects.' For that reason, I count it as a version of the one-world/two-aspect reading.

The label is not important, however. What is important is that this reading can respect all the textual motivation for the traditional one-world interpretation, while solving the most difficult problems that interpretation faces. The reading also has some advantages over the most prominent versions of the two-world reading, though I won't attempt a full comparison with the two-world reading here.

Section 1 below describes four problems for the traditional one-world reading. Section 2 presents the philosophical core of my proposal, which develops an Aristotelian notion of an entity I call, borrowing Kit Fine's terminology, a 'qua-object.' Section 3 applies this notion to Kant's idealism, shows how the resulting interpretation fits the text as well as the traditional one-world interpretation does, and considers how the proposal relates to several extant interpretations. Section 4 shows how the fully-developed qua-object interpretation solves the problems from Section 1.

Since the interpretation I propose has a straightforward basis in the text, some of my claims resemble those made by other one-world interpreters, especially those who privilege the 'two aspect' formulation. None of them, however, seem to have appreciated either how such formulations differ from the traditional focus on identity, or the degree to which this alternative approach can address problems for the one-world reading. If the qua-object interpretation incorporates the more plausible aspects of previous one-world views while avoiding misleading formulations, all the better.

A final note: the reading I favour is most closely related to so-called 'moderate, metaphysical one-world' readings. Such readings are too metaphysical for some of Kant's interpreters, and the present paper can only claim to be one part of a defence of such an

numerically-existentially identical" (G. Prauss, Erscheinung bei Kant: Ein Problem der "Kritik der der reinen Vernunft" (Berlin: Walter de Gruyter, 1974), at p. 22 (my translation)). See also M. Willaschek, 'Die Mehrdeutigkeit der Unterscheidung zwischen Dingen an sich und Erscheinungen bei Kant. Zur Debatte um Zwei-Aspekte- und Zwei-Welten-Interpretationen des transzendentalen Idealismus', in V. Gerhardt, R.-P. Horstmann and R. Schumacher (eds.), Akten des IX. Internationalen Kant-Kongresses, Vol. 2 (Berlin: Walter De Gruyer, 2001), pp. 679-690., at p. 679. Henry Allison, notably, deliberately avoids talk of identity: cf. H. Allison 1996. Idealism and Freedom (Cambridge UP, 1996), pp. 11-12. 
approach. Like others, I believe there are decisive objections to 'epistemological' or 'methodological' one-world readings, ${ }^{6}$ but directly criticising those readings is not my aim here.

\section{Problems for the traditional one-world interpretation}

The traditional one-world interpretation holds that appearances and things in themselves are the same things, where 'the same' is typically understood as strict identity. This interpretation faces at least four problems.

\subsection{Contrary empirical properties problem}

According to the traditional one-world reading, appearances are identical to things in themselves. By the indiscernibility of identicals, this implies that they cannot differ in their properties. Yet Kant is quite explicit that appearances are spatiotemporal and that things in themselves are not. In the Prolegomena, he states that he limits sensory intuition "only to the extent that in no instance whatsoever, not even in the pure intuitions of space and time, does it represent anything more than mere appearances of these things, and never their quality in themselves" (Proleg. 4:293, cf. A276/B332). Though one-world interpreters have offered a variety of responses, many of Kant's readers remain unconvinced that any oneworld reading can make literal sense of these passages. ${ }^{7}$

\footnotetext{
${ }^{6}$ E.g. H. Robinson, 'Two perspectives on Kant's appearances and things in themselves', Journal of the History of Philosophy 33 (1994), pp. 411-41, J. Van Cleve, James, Problems from Kant (Oxford UP, 1999), K. Ameriks, Interpreting Kant's Critiques (Oxford: Clarendon Press, 2003), L. Allais, 'Kant's one world: interpreting 'transcendental idealism', British Journal for the History of Philosophy 12 (2004), pp. 655-684, K. Setiya, 'Transcendental Idealism in the Aesthetic', Philosophy and Phenomenological Research 68 (2004), pp. 63-88., and T. Rosefeldt, 'Dinge an sich und sekundäre Qualitäten,' in J. Stolzenburg (ed.), Kant in der Gegenwart (Berlin and New York: Walter de Gruyter, 2007), pp. 167-209. Ameriks', Allais' and Rosefeldt's readings are the closest to the one proposed below. The best known defences of the epistemological one-world approach are Prauss and H. Allison, Kant's Transcendental Idealism, $2^{\text {nd }}$ edition (New Haven: Yale University Press, 2004). ${ }^{7}$ The best-known responses come from advocates of the epistemological one-world reading such as Allison. For dissatisfaction with Allison-style responses to this and the following puzzles, see Van Cleve, 149ff., Y. Senderowicz, The Coherence of Kant's Transcendental Idealism (Dordrecht: Springer, 2005), pp.6-9, R. Hanna, Kant, Science, and Human Nature (Oxford UP, 2006), p. 423, A. Wood, P. Guyer, and H. Allison, 'Debating Allison on Transcendental Idealism', Kantian Review 12 (2007), pp. 1-39., at p. 13ff., and R. Walker, 'Kant on the Number of Worlds', British Journal for the History of Philosophy 18 (2010), pp. 821-843, at. p. $824 \mathrm{ff}$.
} 
The situation is best understood as a dilemma: either the one-world interpreter must deny that Kant ascribes spatiotemporal properties only to appearances, or she must make it clear that she does not mean to identify appearances with things in themselves. The former option faces the difficulty of Kant's apparent statements to the contrary, whereas the latter faces the difficulty of losing any clear sense in which appearances and things in themselves are the same things. The following problems reinforce this dilemma.

\subsection{Noumenal counting problem.}

If, as the one-world interpreter holds, appearances are the same things as things in themselves, then it would seem to follow that our knowledge about the number of appearances would tell us something about the number of things in themselves. Yet knowing facts about the latter would violate Kant's well-known epistemological strictures. However these strictures should be understood, it is fairly clear that we should not be able to know how many things in themselves there are. Kant himself seems to state explicitly that the number of objects of experience and of things in themselves can diverge:

it is a complete misunderstanding of the theory of sensible objects as mere appearances, to which something non-sensible must be attached, if one imagines... that what is meant thereby is that the super-sensible substrate of matter will be divided according to its monads just as I divide matter itself. ${ }^{8}$

Ralph C. S. Walker has described this as "[t]he real difficulty for the one-world interpretation. ${ }^{\prime 9}$ It has been consistently ignored by one-world interpreters. ${ }^{10}$ As before, the one-world interpreter must choose between rejecting the natural reading of the text or

\footnotetext{
8 "On a discovery according to which any new Critique of Pure Reason is rendered dispensable by an older one', 8:209n., translation from H. Allison, P. Heath, G. Hatfield, and M. Friedman (trans. and eds.), Theoretical Philosophy after 1781 (Cambridge UP, 2002).

${ }^{9}$ Walker, p. 824. Versions of this challenge are found in K. Ameriks, Kant's Theory of Mind, $2^{\text {nd }}$ edition (Oxford UP, 2000), p. 145, C. D. Broad, Kant: An Introduction (Cambridge UP, 1978), p.277, T. Pogge, 'Erscheinungen und Dinge an sich', Zeitschrift für philosophische Forschung 45 (1991), pp. 489-510, at p. 495, R. Adams, 'Things In Themselves', Philosophy and Phenomenological Research 57 (1997), pp. 801-825, at p. 824, Van Cleve, pp. 160ff., E. Watkins, 'The Antinomy of Pure Reason, Sections 3-8', in G. Mohr and M. Willaschek (eds.), Immanuel Kant, Kritik der reinen Vernunft, (Berlin: Akademie Verlag, 1998), p. 493 and Schulting, p. 13.

${ }^{10}$ The only exception I am aware of is J. N. Finlay, Kant and the Transcendental Object (Oxford: Clarendon Press, 1981), who simply accepts that we have knowledge of the number of things in themselves.
} 
finding some sense of 'same things' that, unlike identity, allows for numerical divergences. But if appearances and things in themselves do not even share numerical properties, then it becomes hard to see how they could be the same things in any significant sense.

\subsection{Mind-dependence problem}

Kant explicitly asserts that appearances are mind-dependent. For instance: "if I were to take away the thinking subject, the whole corporeal world have to disappear" (A383). ${ }^{11}$ By contrast, the very notion of a thing in itself seems to imply mind-independence. So the one-world interpreter must either reject the natural reading of these passages, or try to find a sense of sameness that, unlike identity, allows for appearances and things in themselves to be the same things while allowing only the former to be mind-dependent. But it is hard to see what sense of sameness would do the job.

\section{4 'Mere representations' problem}

The final problem is closely related to the previous one. In various passages, Kant appears to directly affirm one of the defining statements of the traditional two-world reading, namely, that appearances just are representations. For instance:

everything intuited in space or in time, hence all objects of an experience possible for us, are nothing but appearances, i.e., mere representations, which, as they are represented, as extended beings or series of alternations, have outside our thoughts no existence grounded in itself (A490-91/B518-19) ${ }^{12}$

Provided that things in themselves are not mere representations, we seem to have a deep divide between appearances and things in themselves. The one-world interpreter's dilemma may appear fatal. Simply ignoring passages like the above is unattractive, but what sense of 'same things' could bridge the spatiotemporal, numerical, etc. gap between appearances and things in themselves?

\footnotetext{
${ }^{11}$ See also A42/B59, A127, A370, A375n., A507/B535. See Schulting, pp. 14-15.

${ }^{12}$ See also A30/B45, A101, A104, A369-70, A372, A375n, A385, A494/B522, Proleg. 4:288. For the role of such passages in challenging the one-world view, see, e.g., Robinson, Van Cleve, pp. 6ff., Wood, p. 64, Schulting, p. 10.
} 
This challenge can be met, I think. The key is to identify the right notion of 'same things.' Doing so requires reconsidering what exactly appearances and things in themselves are.

\section{Qua-Objects}

The philosophical core of my interpretation hinges on a semi-technical notion, which I elaborate in fairly broad strokes. Though my elaboration is novel, the notion itself comes from Aristotelian metaphysics. Since my general aim here is interpretive, I do not claim to offer a full philosophical development of the notion. But I do hope to show that it has deep enough historical roots and is intelligible enough that it can play a central role in a charitable interpretation of Kant.

\subsection{Qua-objects introduced}

Very broadly speaking, philosophers in the Aristotelian tradition have taken ordinary objects to involve two basic ingredients: matter (or substance or subject) on the one hand, and forms (or properties or features or qualities or predicates) on the other. The former is primarily responsible for the individuality or particularity of the thing, and the latter for what or how the thing is. Within forms, there is a further distinction between those that are essential to the object, those that are necessary but not essential, and those that are merely accidental.

Beyond that, the details of the view can be spelled out in very many ways. There are questions about whether matter is utterly featureless, about what exactly deserves the title of 'substance,' about how forms relate to universals and to the predicates of natural language, and about how exactly forms and matter are connected.

Most of these details don't matter for my purposes, though I will return to the issue of whether substance is featureless in Section 3.2. What matters most is the two-ingredient analysis of objects. In what follows, I call these ingredients 'substances' and 'properties,' and call any ingredient that the object could not exist without 'necessary' (generally avoiding the more contentious term 'essence'). This terminology ignores several traditional distinctions, 
but is precise enough for my purposes. Which ingredients are necessary for an object is a non-trivial metaphysical question. On one intuitive approach, however, the substance and some (but not all) of the properties will be necessary (especially if, like Descartes, we think of any substance as bringing certain properties with it).

With that in place, we can represent an arbitrary object as follows:

object: $\mathbf{s 1}+\mathbf{P} 1+\mathbf{P} 2+\mathrm{P} 3+\mathrm{P} 4 \ldots$,

where s1 is the substance and p1, p2, etc. are the properties. Bold indicates what is necessary for the object, that is, those ingredients that this object could not exist without. The ' + ' is most easily understood as referring to mereological composition, though it need not be. So a lump of gold might be understood as:

lump: S1 + PHYSICALLY EXTENDED + CONTAINS GOLD + ...WEIGHS 10 KILOGRAMS + PURCHASED ON MONDAY + CAST INTO KANT-SHAPE ON TUESDAY + MELTED DOWN ON WEDNESDAY + CAST INTO HEGEL-SHAPE ON THURSDAY...

Given this analysis, the question arises of whether anything else exists in virtue of those ingredients being together. To illustrate that question, consider a 'remix' of the lump:

lump-qua-Kant-shaped: s1 + PHYSICALLY EXTENDED + CONTAINS GOLD + KANT-SHAPED + WEIGHS 10 KILOGRAMS + CAST INTO KANT-SHAPE ON TUESDAY + MELTED DOWN ON WEDNESDAY...

Here, we've taken one property that was present in the lump and made it necessary to an entity that involves the same substance and some (but not all) of the same properties.

Nothing forces one to admit that this latter description corresponds to anything real, even if one accepts the existence of the original lump. However, the description would be one way of construing the referent of talk of 'the Kant-shaped lump,' 'the lump as Kantshaped' or even 'the Kant statue' (in addition to 'the lump-qua-Kant-shaped'). ${ }^{13}$ Moreover,

\footnotetext{
${ }^{13}$ Cf. G. Matthews, 'Accidental Unities', in M. Schofield and M. Nussbaum (eds), Language and Logos (Cambridge UP, 1982), and M. Rea, 'Sameness Without Identity: An Aristotelian Solution to the Problem of Material Constitution', Ratio 11 (1998), 316-28 on 'accidental unities' and K. Fine, 'Acts, events and things', in W. Leinfellner, E. Kraemer, and J. Schank (eds.), Sprache und Ontologie. Akten des sechsten Internationalen Wittgenstein-Symposiums, 23. bis 30. August 1981, Kirchberg am Wechsel (Osterreich) (Wien: Holder-Pichler-
} 
accepting the existence of the lump-qua-Kant-shaped does not involve accepting the existence of any new fundamental entities (substances or properties). The lump-qua-Kantshaped does have some new properties (e.g. beginning to exist on Tuesday), but these properties arise straightforwardly out of the earlier properties (e.g. being cast into Kantshape on Tuesday).

Following Fine, I call entities like the lump-qua-Kant-shaped 'qua-objects.' The basic recipe for a qua-object is straightforward, even if the details are not. An object-qua- $F$ is formed by taking the substance of an object, making F-ness necessary to it, and adding other properties accordingly.

The 'accordingly' calls for clarification. For what follows, the most important constraint is that the properties of the qua-object must either be those of the original object, or else arise straightforwardly from the latter; nothing fundamentally new can be added. Beyond that constraint, the 'accordingly' will have to be spelled out via non-trivial principles about the connections of properties (e.g. if $x$ is necessarily Kant-shaped then $x$ cannot be Hegel-shaped). The metaphysics of properties is not my main concern here, so the examples below are based on what strike me as intuitive views about the connections of properties. For my larger purposes, a number of other views would do just as well.

Three further points about qua-objects: First, qua-objects are ontologically parasitic on the objects from which they are derived. A symptom of this is asymmetric ontological dependence: the lump could have existed without the lump-qua-Kant-shaped (e.g. if the lump had never been cast into Kant-shape), but not vice-versa. Optionally, one could understand talk about qua-objects as being merely a reified way of talking about the properties of the original object (e.g. "the lump-qua-Kant-shaped is destroyed" is just a way of saying that "the lump is no longer Kant-shaped"). Second, nothing forces us to say that qua-objects are mind-dependent entities, so long as their ingredients are not minddependent. This is because, as defined, the notion is fundamentally metaphysical, despite resembling certain intentionally-loaded notions (e.g. 'considering a lump as Kant-shaped').

Tempsky, 1982), pp. 97-105 and P. Keller, 'Qua qua qua' (manuscript) on 'qua-objects.' None of these writers present their notions in quite the way I do here. Obviously, there are other views of the relationship between lumps and statues and other ways of understanding 'qua' locutions that I'm not considering. 
Third, we can see that there is a clear sense in which the lump and the lump-quaKant-shaped are the same thing. ${ }^{14}$ Though they are not identical (since they differ in some properties), these two entities share several ingredients. Most importantly, they share a substance - the very ingredient responsible for particularity. In addition, they share instances of properties. Admitting the existence of lump-qua-Kant-shaped does not force us to say that, on Wednesday, there is more than one instance of Kant-shaped-ness, or that a scale with the lump-qua-Kant-shaped on it will register 20 kilograms (10 for the lump +10 for the remix).

This last point naturally extends to qua-objects formed from the same original object. Consider the lump-qua-melted-down-on-Wednesday. This will share the same substance and many of the same instances of properties with the lump-qua-Kant-shaped, and so they will also be, in the above sense, the same thing.

\subsection{Qua-objects extended}

So far, the notion of qua-objects I've described is more or less in line with the way Fine and others have developed one strand of Aristotle's thought. For my interpretive aims, however, I need to extend the notion in two ways.

The first extension concerns what can be used for $F$ in forming an object-qua- $F$. The earlier example used a (fairly) determinate property: being Kant-shaped. But there is no obvious reason not to allow less determinate properties. In that case we would allow quaobjects such as:

lump-qua-philosopher-shaped: s1 + PHYSICALLY EXTENDED + CONTAINS GOLD + PHILOSOPHERSHAPED + MOULDED INTO KANT-SHAPE ON TUESDAY + MELTED DOWN ON WEDNESDAY + CAST INTO HEGEL-SHAPE ON THURSDAY..

Whereas the lump-qua-Kant-shaped was necessarily Kant shaped, this qua-object is not. It is, however, necessarily shaped like some philosopher. If it had existed without being Kantshaped, it would have had to have been Hegel-shaped, or Plato-shaped, or Aquinas shaped, etc.

\footnotetext{
${ }^{14}$ Rea describes a relation like this as a form of sameness without identity.
} 
The second extension concerns what objects can be used in forming an object-qua-F. The examples so far have focused on single objects, but non-monadic properties allow us to form more complex qua-objects. Say that Charles $(\mathbf{s} 2+$ human+...) and David $(\mathbf{s 3}+$ human $+\ldots)$ are siblings. Then we can have:

\section{Charles-and-David-qua-Siblings: S2+s3+HUMAN+SIBLINGS... ${ }^{15}$}

There are further questions one might raise about the formation of qua-objects, but this much will do for my purposes. I now turn to describing two species of qua-objects.

\subsection{First species: Appearance qua-objects}

Say that Charles and David are moving the statue, and that, all together, they appear like a three-headed monster. If we accept qua-objects according to the above conception, then we have:

\section{Charles-and-David-and-statue-qua-appearing: s1+s2+s3+INVOLVES-TWO-} HUMANS+CONTAINS-GOLD+APPEARS-SOME-WAY+ APPEARS-THREE-HEADED-MONSTER-LIKE

As before, admitting the existence of such a qua-object doesn't involve admitting anything fundamentally new to our ontology. The ingredients of this qua-object are all derived from Charles, David and the statue. Making use of the extensions from the previous sub-section, this qua-object involves a less determinate property (appearing some way) and three ordinary objects. Two features of appearance properties are important here. First, appearance properties can involve multiple objects. Only together do Charles, David and the statue appear like a three-headed monster. Second, appearance properties depend on minds (at least essentially), so a qua-object like the above will be mind-dependent, even

\footnotetext{
${ }^{15}$ Elsewhere I discuss a related notion: effect-relative composition. The governing principle for this notion was that if some group of things jointly has a certain number of effects, then, relative to those effects, those things compose that many objects: C. Marshall , 'Kant's Metaphysics of the Self' Philosophers' Imprint 10 (2010), pp. 1-21, at pp. 14ff. This can be seen as an instance of qua-object formation: if some number things have a certain number of effects, then, for each effect $E$, there exists a qua-object of the form [thing-or-things]-quacause-of-E.
} 
though not all qua-objects are. ${ }^{16}$ In what follows, I call qua-objects formed with appearance properties 'appearance qua-objects.'

\subsection{Second species: In-themselves qua-objects}

Not surprisingly, the second species of qua-objects is built from properties objects have in themselves. Talk of how things are in themselves has been understood in various ways. For reasons that will become apparent, the sense I give this talk is built on a contrast with appearance properties. So things-qua-in-themselves are things-qua-having-onlyproperties-other-than-appearance-properties. This means that Charles-and-David-andstatue-qua-in-themselves would not have any appearance properties, but (for all that has been said so far) could have relational properties such as causally affecting each other. ${ }^{17}$ It will also include any intrinsic properties of the original objects (in some form). For instance:

Charles-and-David-and-statue-qua-in-themselves: s1+s2+s3+HAVING-ONLY-PROPERTIESOTHER-THAN-APPEARANCE-PROPERTIES+INVOLVES-TWO-HUMANS+CONTAINS-GOLD+CAUSALLYINTERACTING-WITH-EACH-OTHER...

I call entities such as this 'in themselves qua-objects.' As before, admitting the existence of such qua-objects doesn't involve admitting any new fundamental entities to the ontology. The ingredients of this qua-object are again all derived from Charles, David and the statue. Moreover, some of these ingredients (including the substances) are shared with the

\footnotetext{
${ }^{16}$ This is because a subject (to which the thing appears) is one of the relata of the appearance property. This does not mean that the subject must be an ingredient of the qua-object, though it does make the property subjective. For a useful discussion of such subjectivity, see Rosefeldt, pp. 178ff and K. Ameriks, 'Kant's Idealism on a Moderate Interpretation', in Schulting and Verburgt (eds.), Kant's Idealism: New Interpretations of a Controversial Doctrine (Dordrecht: Springer, 2011), pp. 29-53, at pp. 30ff.

${ }^{17}$ If, as Rae Langton suggests, all relations are appearance properties (see R. Langton, Kantian Humility (Oxford UP, 2009, and Van Cleve, p. 150), then a non-distributive reading of 'in themselves' would allow for relations between the things in themselves (ruling out only relations to us). Langton herself uses a distributive reading, which leads to problems such as those discussed in K. Ameriks, 'Review of Rae Langton, Kantian Humility', Philosophical Books 41 (2000), pp. 111-113 (also cf. A42/B59). I think Langton is right to give the intrinsic a central role in understanding things in themselves, but do not think she is right to claim that all relations are appearances.
} 
appearance qua-object from the previous sub-section. ${ }^{18}$ This means that, while not identical, these qua-objects are, in the sense described, the same thing.

\subsection{Epistemic gap between appearance qua-objects and in-themselves qua-objects}

So far, I have developed the notion of a qua-object in metaphysical terms. The notion does, however, have certain epistemological implications. ${ }^{19}$ While full knowledge of the original object presumably could yield full knowledge the qua-objects derived from it, knowledge of one qua-object needn't provide knowledge of others formed from the same original object.

We see this with the applications of the notion just described. Even though an appearance qua-object is the same thing as an in-itself qua-object, one might know much about the former while knowing nothing specific about the latter. Returning to the above example, someone who saw Charles, David and the statue from a distance might know that there is an appearance qua-object, and be able to give at least a partial description of it:

Something-or-things-qua-appearing: S?+?...+ APPEARS-SOME-WAY+APPEARS-SLOWMOVING+APPEARS-MONSTER-LIKE+...

The most this person could infer about the corresponding in-itself qua-object, however, might be that there is:

That-thing-or-things-qua-in-themselves s?+?...+ HAVING-ONLY-PROPERTIES-OTHER-THANAPPEARANCE-PROPERTIES +HAS-INTRINSIC-PROPERTIES-CONTRIBUTING-TO-MONSTER-LIKENESS+?...

In other words, there is an epistemic gap between appearance qua-objects and inthemselves qua-objects. How strong this gap is depends on the case. If there's no reason to doubt that an object appears to be just as it is in itself, then the gap is weak enough that

\footnotetext{
${ }^{18}$ I see no reason to deny that these qua-objects can share some property instances. But the most important consequences of the present proposal do not hinge on this. A metaphysical version of Henry Allison's 'abstraction' account of things in themselves could be constructed in terms of qua-objects (though, as far as I can tell, that would only help with the contrary empirical properties problem).

${ }^{19}$ Such implications were part of Aristotle's interest in such notions. Cf. his discussion of the masked man puzzle in De Sophisticis Elenchis §24.
} 
only a radical sceptic would worry about it. But if we have grounds for thinking that an object appears in a way that differs from how it is in itself, then the gap will be strong. Not only may we not know how many substances are involved, but we may know nothing specific about the properties of the in itself qua-object (other than, trivially, that it has properties other than appearing).

\subsection{Appearance properties and idealism}

This brings me to the last piece of the philosophical core of my proposal, which is logically independent of the above: the identification (in the strict sense) of spatiotemporal properties with certain appearance properties. If, say, the property of having a certain shape is identified with the property of appearing a certain way, then since appearance properties are mind-dependent, it would follow that shape properties are also minddependent. It does not immediately follow from this that there will be a strong epistemic gap between appearance qua-objects and in themselves qua-objects, but it is compatible with such a gap. We would have reason for accepting a strong gap if, say, we knew that the mind played an active role in shaping how things appear. ${ }^{20}$

Nothing about the notion of a qua-object forces or precludes this identification of properties. So the notion does not preclude taking the relevant appearance qua-object to have a mind-independent substance as an ingredient.

\section{The Qua-Object Reading of Appearances and Things in Themselves}

The core of my interpretive proposal is to identify appearances with objects-quaappearances and things in themselves with objects-qua-in-themselves, where spatiotemporal properties are identified with certain appearance properties. In Section 4, I explain how this proposal can solve the interpretive puzzles from Section 1. The present section details the proposal along with its textual basis, considers a potential objection, and describes how the proposal relates to existing interpretations.

\footnotetext{
${ }^{20}$ There is an underlying question here concerning the so-called 'neglected alternative' challenge to Kant's idealism, which I cannot directly address here.
} 


\title{
3.1 Textual basis for the qua-object reading
}

Consider two of the passages which seem to most directly motivate the traditional one-world reading:

\begin{abstract}
if we were to assume the distinction between things as objects of experience and the very same things as things in themselves, which our critique has made necessary, were not made at all, then... I would not be able to say of one and the same thing, e.g., the human soul, that its will is free and yet it is simultaneously subject to natural necessity (Bxxvi-xxvii)

We have... wanted to say that all our intuition is nothing but the representation of appearance; that the things that we intuit are not in themselves what we intuit them to be, nor are their relations so constituted in themselves as they appear to us (A42/B59)
\end{abstract}

These passages imply that distinction between appearances and things in themselves concern the same things, hence their amenability to the one-world reading. Note, however, that Kant does not say here (or anywhere else!) that appearances and things in themselves are identical (identisch). Rather, he talks of things as they are in themselves and those things as they appear to us. The implication is that these are the same things, but we can easily understand this as describing non-identical qua-objects formed from the same things.

Now, Prauss and Allison have famously proposed that such locutions ('as they appear') should be understood in an adverbial way, and so as merely specifying certain ways of considering or representing objects. On their approach, these locutions have no metaphysical import. ${ }^{21}$ This does not exactly fit the above passages, however. There, Kant uses these locutions in clauses where there is no representational verb they might naturally be taken to modify. This suggests, then, that these locutions are meant to have metaphysical import. Reading these passages as describing qua-objects makes straightforward sense of that.

Notice that in the above passages, Kant primarily talks of things 'as they appear' or 'as appearances'. In other passages, however, he speaks just of 'appearances.' I propose that the latter sort of talk be taken as elliptical for the former. That is, when Kant says that

\footnotetext{
${ }^{21}$ Prauss, pp. 13ff., Allison, Kant's Transcendental Idealism, pp. 50ff. Note that it does not follow from the fact that a phrase has representational import that it lacks metaphysical import. Perhaps for this reason, Prauss and Allison grant that the passages that directly support their non-metaphysical reading are uncommon.
} 
"all objects of an experience possible for us, are nothing but appearances" (A491/B519), we should understand this as saying that "all objects of an experience possible for us are nothing but things as they appear."22 The above passage from A42/B59 above supports this, as does the following: "we can have cognition of no object as a thing in itself, but only insofar as it is an object of sensible intuition, i.e., as an appearance" (Bxxvi). ${ }^{23}$ Of course, having to read 'appearances' as elliptical is a (minor) cost for my proposal, but it is a cost that most traditional one-world readings will share.

On this interpretive approach, then, Kant's distinction between appearances and things in themselves is a distinction between things-qua-appearances and things-qua-inthemselves, for the same things. By itself, the distinction does not entail that these quaobjects differ significantly: for all that has been said so far, things might appear to be exactly as they are apart from how they appear. This is as it should be: the appearance/thing in itself distinction is one that Kant does not argue for, but he does take himself to argue for the ideality of objects' empirical properties and our ignorance of things in themselves, so the distinction should not obviously imply these conclusions. ${ }^{24}$ Yet, for interpretive reasons, our understanding of the distinction should be compatible with the properties of the two diverging.

This divergence will be especially marked if normal empirical properties are identified with certain appearance properties. The grounds for attributing that view to Kant are quite strong, and I have nothing to add on that front. ${ }^{25}$ I should note that for Kant, the relevant appearance properties will be the result of a sophisticated process of synthesis and judgement: these properties are nowhere near as simple as the Lockean secondary qualities Kant compares them with (cf. Prolegomena 4:289). As suggested above, the mind's role in

\footnotetext{
${ }^{22}$ At the same time, I think 'appearance' ('Erscheinung') has the same sort of vehicle/content ambiguity in Kant that it has in ordinary language. For that reason, I do not claim that all of his uses of 'appearance' are elliptical for 'things as they appear,' only those with 'appearance' in the content sense. On the two senses of 'appearance' see Willaschek, 687.

${ }^{23}$ The same holds for Kant's talk of 'phenomena': "if we call certain objects, as appearances, beings of sense (phaenomena), because we distinguish the way we intuit them from their constitution in itself, then it already follows from our concept that to these we oppose... noumena" (B306).

${ }^{24}$ Here I agree with Ameriks, then, in denying that Kant has a short argument to his idealism.

${ }^{25}$ See especially the arguments in L. Allais, 'Kant's Idealism and the Secondary Quality Analogy', Journal of the History of Philosophy 45 (2007), pp. 459-84, Rosefeldt, and Ameriks, 'Kant's idealism on a moderate interpretation' (though they formulate the relevant claim slightly differently).
} 
creating appearance properties is probably key to the epistemic gap between appearances and things in themselves.

The qua-object reading of the distinction supports the mind-dependence of appearances. If things appear as they do in virtue of certain facts about the mind (e.g. our forms of intuition), then the properties of things-qua-appearances will be mind-dependent. Since a thing-qua-appearance necessarily has the property of appearing, and one (de re) necessary mind-dependent property makes a thing mind-dependent, it follows that thingsqua-appearance (and so, for Kant, objects of experience) are mind-dependent. ${ }^{26}$

At this point, one might ask: why identify both appearances and things in themselves with qua-objects? After all, there is another option: identifying one or the other of them with the original objects from which the qua-objects are derived (e.g. $\mathbf{s 1}+$ APPEARANCE PROPERTIES + NON-APPEARANCE PROPERTIES) ${ }^{27}$ The reason not to identify either appearances or things in themselves with the original objects comes from the status of the original objects' appearance properties. Since some of these properties are spatiotemporal properties, and things in themselves lack those properties, the original objects cannot be identified with things in themselves (in-themselves qua-objects). The matter is slightly more complicated with appearances. Strictly speaking, many of the virtues of the qua-object reading would be preserved if appearances (and so, objects of experience) were simply identified with the original objects. Yet if we hold (as Kant seems to) that appearances are necessarily spatiotemporal (e.g. the lump is necessarily physically extended), but that appearances properties are not necessary properties for the original objects, then we cannot make that identification. This will mean that, given Kant's view, the original lump in Section 2 would itself be a qua-object, and that the lump-qua-Kant-shaped would be a second-order quaobject (a qua-object parasitic on another qua-object).

Before going on, I should emphasize that my textual claim is only that the qua-object reading respects the text as well as traditional one-world readings do. The main reason for preferring the qua-object reading over the traditional reading is that only the former can solve the problems described in Section 1.

\footnotetext{
${ }^{26}$ The same holds for empirical substance (the subject of the First Analogy) and empirical matter, which should not be confused with the mind-independent substance that forms the core ingredient of ordinary objects (for a relevant discussion, see Setiya, pp. $82 \mathrm{ff}$.).

${ }^{27} \mathrm{~A}$ similar question faces other two-aspect accounts (cf. Allison Idealism and Freedom, p. 16).
} 


\subsection{Two ways of understanding the substance in qua-objects}

In introducing the notion of a qua-object, I set aside the question of whether the particularity-conferring ingredient (the substance) was itself featureless or not. My way of representing qua-objects, which lists properties separately from the substance, may suggest that the substance is something distinct from any property, and so itself featureless. This view is not essential to my proposal, however. It is therefore worth considering how the proposal would look if we assume that substances involve properties in the way that Descartes, for instance, assumes that some substances involve thought, and others extension. Following Descartes, I'll call any property that is involved in a substance in that way a 'principal attribute. ${ }^{28}$

Say that $P$ is a principal attribute of some substance $S$. In that case, any qua-object formed with $\mathrm{S}$ as an ingredient will also involve $\mathrm{P}$. If $\mathrm{P}$ is the only principal attribute of $\mathrm{S}$, then it is natural to think that S-qua-P would simply be identical to $\mathrm{S}$. In applying this conception of substance to Kant, the central question will be whether the principal attributes are appearance properties or not, and if not, whether they are all of the appearance properties. If any principal attribute of $S$ is an appearance property, then there can be no in-itself qua-object involving $\mathrm{S}$ (given the above definition). So my proposal cannot allow substances with appearance properties as principal attributes (since, for Kant, objects of experience always have corresponding in themselves qua-objects). But there are two workable options. (1) If all the principal attributes are non-appearance properties, and vice-versa, and S necessarily has no appearance properties, then S-qua-in-itself will be identical to S. (2) If the principal attributes of a substance were only some of its nonappearance properties, then S-qua-in-itself would not be identical to $S$, though it would contain S as an ingredient. (1) can only hold for pure noumena, like God (see B71), but (2) would allow for there to be an S-qua-appearance that is not be identical to S-qua-in-itself, though they will be the same thing in the above sense.

\footnotetext{
${ }^{28}$ See $\S 53$ of Part I of Descartes' Principles. Strictly speaking, Descartes' conception of a principal attribute (distinguished from propria) is narrower than this, but that won't matter for my purposes.
} 
The below solutions to the problems from Section 1 do not hinge on whether we allow for principal attributes, so the choice will be primarily a textual one. An advantage of taking any substance to have principal attributes and taking these to be at least some of the object's non-appearance properties is that this would fit with Kant's occasional talk of the substantial (das Substantiale), which he sometimes describes as a (feature-having) ingredient of substances and which he sometimes suggests is the thing in itself. ${ }^{29}$ By contrast, it is less clear that Kant even has a term for a featureless particularity-conferring ingredient of substances (though see his talk of the absolute subject at A348). As far as his larger purposes were concerned, however, Kant could well have (and so, perhaps, should have) remained neutral on this issue.

Because it allows us to make all the properties of a thing perspicuous, l'll continue to represent qua-objects with properties separated from substances, but nothing in the arguments that follow would be lost if the substances were thought of along the lines of (2) above (and, in special cases, along the lines of (1)).

\subsection{Qua-objects and illusions}

Before going on, I want to address another objection that has been raised against two-aspect approaches generally. James Van Cleve objects that spelling out the two aspects in this way implies that appearance is illusion. ${ }^{30}$ Normally, if the way a thing appears radically diverges from how it is apart from the appearance, we would say that the appearance was illusory. Kant is quite explicit, however, that his view of objects as appearances is not about illusion: "If I say: in space and time intuition represents both outer objects as well as the self-intuition of the mind... as it appears, that is not to say that these objects would be a mere illusion" (B69).

On my proposal, objects of experience are appearances, i.e., things-qua-appearing. Once the details about appearance properties are filled in, it will follow that these appear differently than how they are in themselves. There is indeed an intuitive sense of 'illusion'

\footnotetext{
${ }^{29}$ See Reflexion 5292 (18:145), Proleg. 4:333-34, B427. Thanks to a referee from PQ for this suggestion. For concerns about a related view, see Ameriks, Kant's Theory of Mind, $267 \mathrm{ff}$.

${ }^{30}$ Van Cleve, pp. 148-49.
} 
according to which this makes these objects into illusions, but that is not Kant's sense. Kant says explicitly that:

truth and illusion are not in the object, insofar as it is intuited, but in the judgment about it insofar as it is thought. Thus it is correctly said that the senses do not err; yet not because they always judge correctly, but because they do not judge at all" (A293/B350, cf. Proleg. 4:290)

We might disagree with Kant about the nature of illusion, but that is not a point against the sort of reading described above.

\subsection{Relation to other interpretations}

Before showing how the qua-object reading of Kant's distinction solves the puzzles from Section 1, I should say something about how it connects to other recent readings of the distinction. As noted, the qua-object reading provides a sense in which appearances and things in themselves are the same things, but, like the two-world reading, it does not identify them. Like Prauss and Allison's reading, it focuses on Kant's use of 'as' locutions, though unlike their reading, it gives these locutions metaphysical import. Like Langton, it understands things in themselves partly in terms of intrinsic properties, but unlike Langton, (a) it takes intrinsic properties to be only part of how things are in themselves, and (b) it does not identify objects merely with properties, but instead with combinations of substances and properties. ${ }^{31}$ Ralph C. S. Walker has recently suggested that we should understand the appearance/thing in itself distinction in terms of an analogy with how an object appears in a mirror. This metaphor fits well with my proposal, but Walker does not think this justifies any talk of appearances and things in themselves being the same things. ${ }^{32}$ The qua-object reading implies the mind-dependence of the properties of appearances, a claim that has been argued for by one-world interpreters such as Karl Ameriks, Lucy Allais and Tobias Rosefeldt (as well as most two-world interpreters). Ameriks, Allais and Rosefeldt, however, are primarily concerned with the metaphysical status of the properties of objects, and do not go beyond traditional formulations in describing the metaphysical status of the

\footnotetext{
${ }^{31}$ Langton briefly considers something like the view I propose (Langton, p. 20), but quickly rejects it.

${ }^{32}$ Walker, p. 827.
} 
things in question. Doing so leaves them, along with other one-world interpreters, vulnerable to the above objections.

Finally, the present proposal has a certain similarity to the 'intentional object' family of two-world readings. On these readings, objects of experience are intentional objects, i.e. the contents of certain representations. ${ }^{33}$ These interpreters have taken a broadly internalist approach to content, however, so that certain mental entities are sufficient for the existence of these objects. On the other hand, at least some of Kant's texts invite an externalist approach (e.g. A19/B33), according to which part of the content of an intuition is a thing that affects the mind..$^{34}$ This opens the possibility of understanding the content of cognitions as qua-objects that involve (intuited) mind-independent entities as ingredients. If that is right, then identifying objects with the contents of representations would be consistent with a variant of the qua-object reading I have proposed.

\section{How the qua-object interpretation solves the problems}

This section describes how the qua-object reading can solve the puzzles from Section 1. One more piece of terminology will be useful: Say that two qua-objects are 'substancesharing' when they are formed from the same original object (and so therefore share substances, and perhaps property instances). Substance-sharing qua-objects can be said to be the same things, in the sense given above.

\subsection{Solving the contrary empirical properties problem}

The first problem was: if appearances have spatiotemporal properties, and things in themselves do not, then how can they be the same things?

If appearances and things in themselves are substance-sharing qua-objects, then there is no difficulty in allowing that only appearances are spatiotemporal. For if there are

\footnotetext{
${ }^{33}$ For an overview, see R. Aquila, 'Hans Vaihinger and Some Recent Intentionalist Readings of Kant', Journal of the History of Philosophy 41 (2003), pp. 231-250.

${ }^{34}$ For helpful discussions, see L. Allais, 'Kant, non-conceptual content and the representation of space', Journal of the History of Philosophy 47 (2009), pp. 383-413 and A. Mueller, 'Does Kantian mental content externalism help metaphysical realists?', Synthese 182 (2011), pp. 449-473.
} 
things that appear to us in the relevant way, then it will follow from the identification of spatiotemporal properties with certain appearance properties that the things-quaappearances will be spatiotemporal. And if, as also follows from the property identification, the original things are not spatiotemporal in themselves, then the things-qua-in-themselves will not be spatiotemporal. Yet these qua-objects will be the same things, for they will share the same (mind-independent) substance, the source of their particularity.

\subsection{Solving the noumenal counting problem}

The second problem was: if the number of appearances may differ from the number of things in themselves, then how can they be the same things?

As the three-headed monster example above illustrated, knowing that an appearance qua-object exists is compatible with knowing little about its ingredients. So if a tree is an appearance qua-object, then one might know that the tree exists, and yet only be able to describe it as:

Tree: $s ?+? . .+$ APPEARS-SOME-WAY+APPEARS-TO-HAVE-A-TRUNK+APPEARS-TO-HAVE-LEAVES+...

That is, one might know only that there is some thing or things that have certain appearance properties. Now, there is a trivial sense in which one can infer that there is a corresponding thing in itself: the (substance-sharing) in-itself qua-object formed out of the same objects as the tree. Kant sometimes allows such casual references to things in themselves (e.g. B70n.), which suggests that he would allow a trivial sense in which we know something about the number of things in themselves. But in a more important sense, we do not know the numerical properties of any in-itself qua-object. For all we know, the relevant in itself quaobject here could be any of the following:

Cartesian soul tree: S1+THOUGHT+ HAVING-ONLY-PROPERTIES-OTHER-THAN-APPEARANCEPROPERTIES +INVOLVES-ONE-THING+INTRINSIC-PROPERTIES-SUPPORTING-APPEARING-TREE-LIKE+...

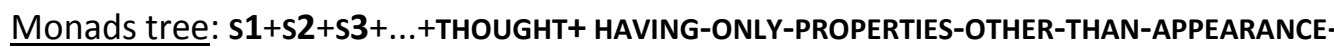
PROPERTIES+INVOLVES-INFINITELY-MANY-THINGS+INTRINSIC-PROPERTIES-SUPPORTING-APPEARINGTREE-LIKE+... 


\section{God-tree: Soo+PERFECTION+ HAVING-ONLY-PROPERTIES-OTHER-THAN-APPEARANCE-}

PROPERTIES+INVOLVES-ONE-THING+INTRINSIC-PROPERTIES-SUPPORTING-APPEARING-TREE-LIKE+...

Etc.

In other words, one could be entirely ignorant of whether the tree in itself (or, more accurately, the tree's substance-sharing in-itself qua-object) involves one substance or many, and whether the substance or substances that are its ingredients are shared with other things. That is, since distinct qua-objects can be formed from the same original objects, the tree and a spatially distinct rock might actually be the same thing (though we could never know this ${ }^{35}$ ):

Tree: SœO+PERFECTION+APPEARS-SOME-WAY+APPEARS-TO-HAVE-A-TRUNK+APPEARS-TO-HAVELEAVES+...

ROCK: SOO+PERFECTION+APPEARS-SOME-WAY+APPEARS-SOLID+APPEARS-ROUND+...

So the qua-object interpretation lets us see why we might remain ignorant of whether fundamental reality is Spinozistic, Leibnizian, or has some other structure. It allows such numerical ignorance, moreover, while maintaining a clear sense in which appearances and things in themselves are the same things. ${ }^{36}$ On this approach, the structure of the empirical world is mind-dependent, even though the things which originally enter into that structure are not.

Not coincidentally, the present interpretation aligns Kant with one strain in Leibniz's thought about empirical objects. Consider two passages:

Matter is an aggregate, not a substance but a substantiatum as would be an army or a flock; and, insofar as it is considered as making up one thing [et en tant qu'on la considere comme faisant une chose], it is a phenomenon, very real, in fact, but a thing whose unity is constructed by our conception. ${ }^{37}$

\footnotetext{
${ }^{35}$ But see A379ff.

${ }^{36}$ It can also make clear sense of Kant's claims that things in themselves cause or ground appearances, claims which the traditional one-object reading has trouble accommodating. Cf. H. Vaihinger, Kommentar zu Kants Kritik der reinen Vernunft (Stuttgart, Berlin, Leipzig: Union Deutsche Verlagsgesellschaft, 1881, 1892), pp. 35ff. All we need is the claim that the properties things have outside of how they appear ground their appearance properties.

${ }^{37}$ Letter to Samuel Masson, translation from R. Ariew and D. Garber (trans. and eds.), Philosophical Essays (Indianapolis: Hackett Press, 1989), p. 227.
} 
although relations [such as aggregation] are the work of the understanding they are not baseless and unreal... the very reality of all things other than simple substances rests only on the foundation of the perceptions or phenomena of simple substances... the only perfect unity that these 'entities by aggregation' have is a mental one, and consequently their very being is also in a way mental. ${ }^{38}$

In both cases, Leibniz seems to be suggesting that certain entities are to be understood as mind-independent things as unified by some conception or perception. This view is, at the least, very close to the one I am ascribing to Kant.

\subsection{Solving the mind-dependence problem}

The third problem was: if appearances are mind-dependent, but things in themselves are not, then how can they be the same things?

This problem threatens even those versions of the one-world reading which hold that everyday objects have mind-dependent properties. It is clear that an object can have some mind-dependent properties while itself being mind-independent. But if, as Kant seems to claim, an object of experience (an appearance) has a mind-dependent existence, it may seem like all properties of that object must likewise be mind-dependent, and that this would preclude that object being, in any sense, the same as a mind-independent thing.

The qua-object reading can accommodate the mind-dependence of appearances (in line with what is suggested in the above passages from Leibniz). An object of experience is a thing-or-things-qua-appearance. Such a qua-object can exist only if the thing has the property of appearing, and since appearing requires a subject or mind for the thing to appear to, the thing-qua-appearance will be mind-dependent. Yet all of this is consistent with holding that such appearance qua-objects are the same thing as things in themselves (in the above terminology: they are substance-sharing qua-objects), where those things in themselves are mind-independent. Returning to the Spinozistic possibility, this means that while

Tree: Sœ+PERFECTION+ APPEARS-SOME-WAY+APPEARS-TO-HAVE-A-TRUNK+APPEARS-TO-HAVELEAVES $+\ldots$

\footnotetext{
${ }^{38}$ Translation from P. Remnant and J. Bennett (trans.), New Essays on Human Understanding (Cambridge UP, 1996 ), p. 145. See Kant's description of Leibniz's view in the K2 lectures at 28:762.
} 
would be mind-dependent,

God-tree: SOO+PERFECTION+ INVOLVES-ONE-THING+INTRINSIC-PROPERTIES-SUPPORTING-APPEARINGTREE-LIKE+...

would not.

\subsection{Solving the 'mere representations' problem}

The final problem may seem to be the most dire for any one-world reading. Kant explicitly and repeatedly states that objects are mere representations. Since things in themselves are clearly not mere representations, how can these be the same thing?

Consider the passage quoted earlier:

everything intuited in space or in time, hence all objects of an experience possible for us, are nothing but appearances, i.e., mere representations, which, as they are represented, as extended beings or series of alternations, have outside our thoughts no existence grounded in itself (A490-91/B518-19)

Above, I suggested that the claim that everyday objects are appearances can be understood as saying that everyday objects are things-qua-appearances. This is consistent with these objects being the same things as things in themselves. Yet this passage states not only that objects of experience are "nothing but appearances," but also that they are "mere representations." This latter statement may seem to overwhelmingly favour a two-world reading.

However, the same approach can be applied here again. When Kant says that objects are "mere representations," we can read him as saying that they are merely "things-qua-represented."

As a two-world interpreter should be quick to emphasise, though, this is not the most natural way to read the claim that "objects are mere representations." If that was all Kant wrote here, then it would indeed be true that the most natural reading of the passage was as a statement of phenomenalism.

That is not all Kant writes, however. After stating that objects are mere representations, Kant says that these objects, "as they are represented, as extended 
beings or series of alternations, have outside our thoughts no existence grounded in itself" ("wie sie vorgestellt werden, als ausgedehnte Wesen oder Reihen von Veränderungen, außer unseren Gedanken keine an sich gegründete Existenz haben"). Kant's full statement therefore has the same structure as the following claim:

A. Neville, as he is represented in the painting, as wise, cannot be found outside of the painting.

The clear implication of this claim is that Neville might be found outside of the painting, though he won't be found being wise. By contrast, there is no such implication in the claim:

B. Neville cannot be found outside the painting.

The reason for this difference is that the qualification "as he is represented in the painting, as wise" in Claim A would be obviously superfluous if Neville were entirely the painter's creation. Since obviously superfluous information is normally left out of assertions, we infer that the qualification was not superfluous, so that Neville might be found outside the painting.

The same point applies to Kant's claim. Say that we accepted that objects were merely constructions out of representations or thoughts. If so, then the claim:

C. Objects, as represented, have no existence outside our representations or thoughts.

would contain an obviously superfluous qualification. Obviously, constructions out of representations cannot exist outside of representations. Assuming Kant obeys the normal rules of conversational cooperation, we should take him to be implying that objects are not mere constructions out of representations. In that case, the twoworld reading of this passage is incorrect. 
On the other hand, the implication in question would make sense if the objects of experience were substance-sharing qua-objects with things in themselves. Contrary to what is often supposed, therefore, passages like A490-1/B518-9 favour the qua-object interpretation over traditional two-world interpretations.

We find similar qualifications, and so similar implicatures, in several of Kant's other statements that appearances are mere representations. ${ }^{39}$ There are, to be sure, some passages that contain no such qualifications. For instance: "what we call outer objects are nothing other than mere representations of our sensibility" (A30/B45). But the longer, qualified statements might be taken as a guide to understanding the unqualified statements. The latter, on their natural reading, might still favour the two-world reading, but the evidence from the 'mere representations' passages now at least cuts both ways. ${ }^{40}$

\section{Conclusion}

The qua-object reading of Kant's distinction between appearances and things in themselves therefore solves four of the most pressing problems that the traditional one-world interpretation faces. It does so, moreover, while retaining a clear sense in which appearances and things in themselves are the same things and retaining all the textual support for the traditional one-reading. At the same time, it gives everyday objects a level of mind-dependence that allows it to respect many of the passages that have motivated the traditional two-world reading.

That said, elements of this reading will seem deeply objectionable to some of Kant's readers. In particular, the qua-object reading rests on certain metaphysical claims about things in themselves and their relationship to the objects of experience. These claims are relatively modest, and I have shown that they can leave us importantly ignorant of many noumenal facts. Still, if we read Kant's epistemological

\footnotetext{
39 "appearances themselves are nothing but sensible representations, which must not be regarded in themselves, in the same way, as objects (outside the power of representation)" (A104). "appearances, as such, cannot occur outside us, but exist only in our sensibility" (A127). My emphases.

${ }^{40}$ Henry Allison makes a similar point about such passages (Allison, Idealism and Freedom, p. 13), though I do not understand his positive proposal about how they are to read.
} 
and representational strictures in a strong way, then even such modest metaphysics may seem to be too much. Like others, ${ }^{41}$ I believe that there is no tension between this and Kant's strictures, but demonstrating that has not been part of my aim here. Likewise, I have only gestured at Kant's nuanced theory of appearances. Understanding the precise nature of any qua-object would require a closer look at these properties - in particular, the way that forms of intuition, concepts and synthesis are involved in the appearances of full-blooded empirical objects.

Fortunately, much of that latter story can be agreed on by one- and twoworld interpreters. I have not offered a full discussion of the two-world reading here, since my own reasons for rejecting it are well articulated by other one-world interpreters. A long-standing motivation for the two-world reading, however, has been the worry that, ultimately, no textually-sensitive one-world reading can be coherently spelled out. That worry is one I hope to have answered. ${ }^{42}$

\footnotetext{
${ }^{41}$ E.g. Adams., Langton, H. Smit, 'The Role of Reflection in Kant's Critique of Pure Reason', Pacific Philosophical Quarterly 80 (1999), pp. 203-223, K. Ameriks, Interpreting Kant's Critiques (Oxford UP, 2003), D. Hogan, 'Noumenal Affection', Philosophical Review 118 (2009), pp. 501-532, K. Schafer, 'Kant's Conception of Cognition and Our Knowledge of Things in Themselves', in K. Schafer and N. Stang (eds.), The Sensible and Intelligible Worlds (Oxford UP, forthcoming).

${ }^{42}$ Thanks to Lucy Allais, Ralf Bader, David Chalmers, Don Garrett, Dana Goswick, Daniel Halliday, Béatrice Longuenesse, James Matthews, Colin McLear, Mike Raven, Jeff Sebo, Tristram Oliver-Skuse, Cristian Soto Herrera, Nick Stang, and audiences at New York University, Frankfurt University, University of Michigan, and La Trobe University. Special thanks to John Morrison, Jonathan Simon and Erica Schumener for helpful discussions about qua-objects.
} 